\title{
Design of Microwave LNA Based on Ladder Matching Networks for WiMAX Applications
}

\author{
Abu Bakar Ibrahim, Ahmad Zamzuri Mohamad Ali \\ Faculty of Art, Computing and Creative Industry, Sultan Idris Education University
}

\begin{tabular}{l} 
Article Info \\
\hline Article history: \\
Received Jan 6, 2016 \\
Revised Jun 29, 2016 \\
Accepted Jul 10, 2016 \\
\hline Keyword: \\
Ladder matching network \\
LNA \\
Radio frequency \\
Ultra wideband
\end{tabular}

\begin{abstract}
Advancement in the wireless industry, internet access without borders and increasing demand for high data rate wireless digital communication moving us toward the optimal development of communication technology. Wireless communication is a technology that plays an important role in current technology transformation. Broadband communication is a method of telecommunication that are available for transmitting large amounts of data, voice and video over long distance using different frequencies. Specifically, Low Noise Amplifier which is located at the first block of receiver system, makes it one of the important element in improving signal transmition. This study was aimed to design a microwave Low Noise Amplifier for wireless application that will work at $5.8 \mathrm{GHz}$ using high-performance low noise superHEMT transistor FHX76LP manufactured by Eudyna Technologies. The low noise amplifier (LNA) produced gain of $16.8 \mathrm{~dB}$ and noise figure $(\mathrm{NF})$ of $1.20 \mathrm{~dB}$. The input reflection $\left(\mathrm{S}_{11}\right)$ and output return loss $\left(\mathrm{S}_{22}\right)$ are $10.5 \mathrm{~dB}$ and $-13.3 \mathrm{~dB}$ respectively. The bandwidth of the amplifier recorded is $1.2 \mathrm{GHz}$. The input sensitivity is compliant with the IEEE 802.16 standards.
\end{abstract}

Copyright (C) 2016 Institute of Advanced Engineering and Science. All rights reserved.

\section{Corresponding Author:}

Abu Bakar Ibrahim,

Faculty of Art, Computing and Creative Industry,

Sultan Idris Education University,

Tanjong Malim, 35900, Perak Malaysia.

Email: bakar@fskik.upsi.edu.my

\section{INTRODUCTION}

Wireless Communication System plays a major role in today's communication by enabling constant connection in $5.8 \mathrm{Ghz}$ frequency. Developments in the wireless industry, internet access without borders and increasing demand for high data rate wireless digital communication moving us toward the optimal development of communication technology. Wireless communication is a technology that plays an important role in the development of the current transformation.

At present, driven by commercial demand for the device is never satisfied with variety of standard low cost and low power mobile radio frequency. Therefore, the researcher and engineers are inspired to develop new communication technique that allows high-performance to low cost product design solutions. Therefore, new technology in communication has been built to meet current demands, for example, wireless communication devices is mobile such as mobile phones pagers, wireless local area network (WLAN), Worldwide Interoperability for Microwave Access (WiMAX), Bluetooth and global positioning system (GPS) phones and ultra wideband (UWB) technologies are all examples of portable wireless communication devices [1].

Broadband communication is a type of telecommunication that available for transmitting the large amounts of data, voice and video over long distance using a different frequency. This is also considered with several technologies with transmission rates above the fastest speed available over a telephone line. In most 
high-frequency communication system, Gallium-Arsenide (GaAs) metal-semiconductor-field-effect transistor (MESFET) and heterojunction bipolar transistor (HBT) show their strong presence in RF product because they give high performance on output power [2].

Usually the first active signal processing block after the antenna is Low noise amplifier (LNA). The amplitude of the received signal at the input LNA may vary from few $\mathrm{nV}$ that is less than $-130 \mathrm{dBm}$ for GPS signals to tens $\mathrm{mV}$. The LNA should be capable of amplifying all these signals without causing any significant distortion. This requires that very little noise from the LNA be introduced to the entire receiver [3],[4].

Figure 1 is the basic to the structure of the RF receiver. As the first block is active after the antenna, LNA has the advantage of high and should be able to reduce noise in the system. The signal received from the antenna will be screened and will be amplified by the LNA and will be sent to the bandpass with a local oscillator. After the demodulated, modulated signal will be used for analog-to-digital (ADC) that converts analog signals to digital signals. Digital signal processing (DSP) will process the digital signal produces by an analog-to-digital (ADC). Therefore, a lot can affect the LNA parameter sensitivity and performance of the overall receiver noise.

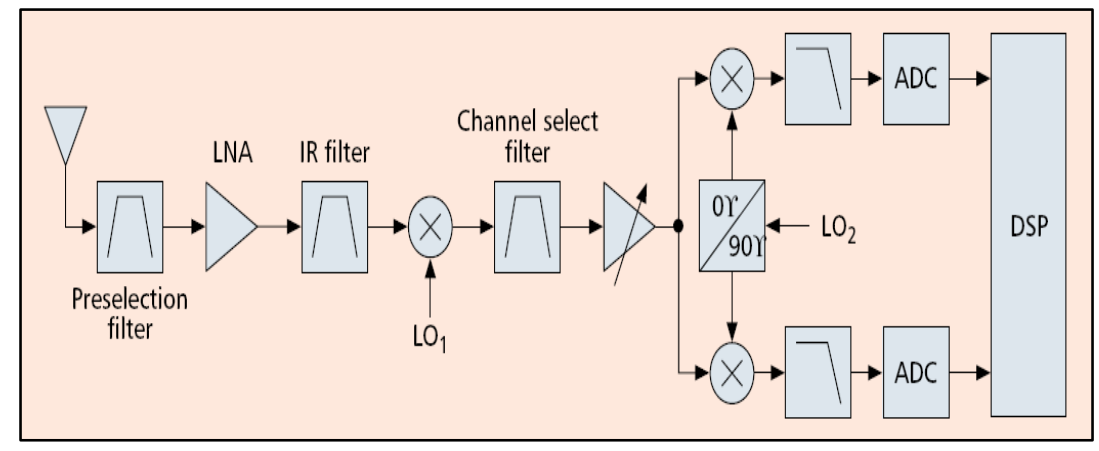

Figure 1. Structure of the RF receiver

The microwave LNA is one of the most important components of in communication receiver. The LNA requires amplifying the received signal with sufficient gain and if possible having a little additional noise. Noise Figure has a major impact on deciding the system's overall in LNA. An LNA can be designed with different circuit topologies; each method proposes to accommodate a wide bandwidth through input and output impedance matching. Such as, shunt-series feedback topology is having broadband behavior as well as good input and output matching characteristics. A capacitor is used in series with feedback to avoid the effect of the output voltage at the optimum basing point in IV curve.

Therefore the higher gain is achieved when the power consumption is low. An inductive load which improves the output noise performance as well as overcomes the gain degradation at higher frequencies is employed. Another inductor is added in series with feedback to give an additional gain at higher frequencies. The inductive degenerated topology had a superior performance as compared to its common gate. Also this topology provides simultaneous input matching and minimum Noise figure [1],[2].

\section{THEORETICAL}

Initially, when designing an amplifier, the input and output matching network are consider to achieve the required stability, small signal gain, and bandwidth. Super high frequency amplifier is a typical active circuit used to amplify the amplitude of RF signal. Basic concept and consideration in design of super high frequency amplifier is presented in this paper. The LNA designed, the formula and equation were referred to [5]. Figure 2, shows a typical single stage amplifier including input output matching networks. The basic concept of high frequency amplifier design is to match input/output of a transistor at high frequencies using S-parameters frequency characteristics at a specific DC-bias point with source impedance and load impedance. Input/output matching circuit is essential to reduce the unwanted reflection of signal and to improve efficiency of the transmission from source to load [5],[6]. 


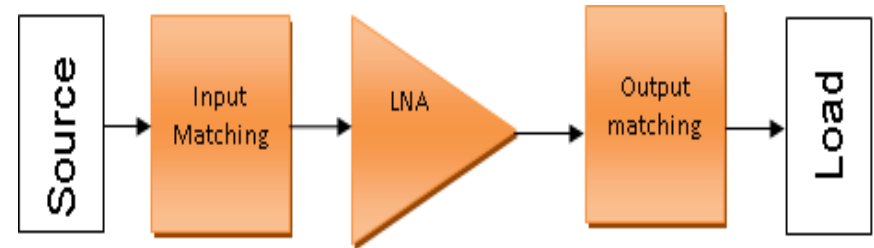

Figure 2. Typical amplifier design

\subsection{Power Gain}

Several power gains were defined in order to understand operation of super high frequency amplifier. Figure 3, show that power gains of 2-port circuit network with power impedance or load impedance at power amplifier. The power amplifiers represented with scattering coefficients are classified into Operating Power Gain, Transducer Power Gain and Available Power Gain [5],[6].

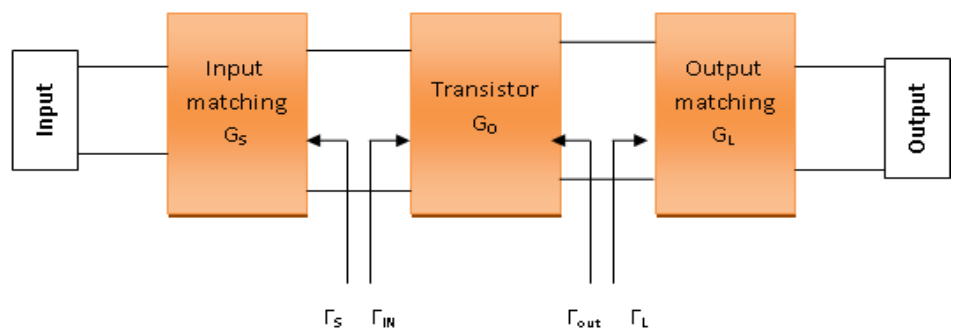

Figure 3. I/O circuit of 2-port network

\subsection{Operating Power Gain}

Operating power gain is the ratio of load power $\left(\mathrm{P}_{L}\right)$ delivered to the load $\left(\mathrm{Z}_{L}\right)$ to input power $\left(\mathrm{P}_{\text {in }}\right)$ supplied to 2-port network. Power delivered to the load is the difference between the power reflected at the output port and the input power, and power supplied to 2-port network is the difference between the input power at the input port and the reflected power. Therefore, Operating Power Gain is represented by

$$
\begin{aligned}
& G_{P}=\frac{\text { Power delivered to the load }}{\text { power supplied to the amplifier }} \\
& =\frac{P_{L}}{P_{\text {in }}}=\frac{1}{1-\left|\Gamma_{\text {in }}\right|^{2}}\left|S_{21}\right|^{2} \frac{1-\left|\Gamma_{L}\right|^{2}}{\left|1-S_{22} \Gamma_{L}\right|^{2}}
\end{aligned}
$$

where, $\Gamma_{i n}$ indicates reflection coefficient of load at the input port of 2-port network and $\Gamma_{s}$ is reflection coefficient of power supplied to the input port.

\subsection{Transducer Power Gain}

Transducer Power Gain is the ratio of $P_{a v s}$, maximum power available from source to $P_{L}$, power delivered to the load. As maximum power is obtained when input impedance of circuit network is equal to conjugate complex number of power impedance, if $\Gamma_{i n}=\Gamma_{s}$, transducer power gain is represented by

$$
\begin{aligned}
& G_{T}=\frac{\text { Power delivered to the load }}{\text { Power Available from the source }} \\
& =\frac{P_{L}}{P_{a v s}}=\frac{\left|S_{21}\right|^{2}\left(1-\left|\Gamma_{S}\right|^{2}\right)\left(1-\left|\Gamma_{L}\right|^{2}\right)}{\left|\left(1-S_{11} \Gamma_{S}\right)\left(1-S_{22} \Gamma_{L}\right)-\left(S_{12} S_{21} \Gamma_{S} \Gamma_{L}\right)\right|^{2}}
\end{aligned}
$$

where, $\Gamma_{L}$ indicates load reflection coefficient. 


\subsection{Available Power Gain}

Available Power Gain, $G_{A}$ is the ratio of $P_{a v s}$, power available from the source, to $P_{a v n}$, power available from 2-port network, that is, $G_{A}=\frac{P_{a v n}}{P_{a v s}}$. Power gain is $P_{a v n}$ when $\Gamma_{i n}=\Gamma_{s}^{*}$. Therefore Available Power Gain is given by:

$$
\begin{aligned}
G_{A} & =\frac{\text { Power available from the amplifier }}{\text { Power available from the source }} \\
& =\frac{P_{a v n}}{P_{a v s}}=\frac{1-\left|\Gamma_{S}\right|^{2}}{\left|1-S_{11} \Gamma_{S}\right|^{2}}\left|S_{21}\right|^{2} \frac{1}{\left|1-S_{22} \Gamma_{L}\right|^{2}}
\end{aligned}
$$

That is, the above formula indicates power gain when input and output are matched [6],[7].

\subsection{Noise Figure}

Signals and noises applied to the input port of amplifier were amplified by the gain of the amplifier and noise of amplifier itself is added to the output. Therefore, SNR (Signal to Noise Ratio) of the output port is smaller than that of the input port. The ratio of SNR of input port to that of output port is referred to as noise figure and is larger than $1 \mathrm{~dB}$. Typically, noise figure of 2-port transistor has a minimum value at the specified admittance given by formula:

$$
F=F_{\min }+\frac{R_{N}}{G_{S}}\left|Y_{s}-Y_{o p t}\right|^{2}
$$

where, $R_{N}$ is the equivalent noise resistance of two ports. $F_{\min }$ is the minimum noise factor obtained by adjusting tuners at the input of the amplifier. The normalized presented by the tuners at $F_{\min }$ is $Y_{\text {opt }}$. With $Y_{s}=Y_{s} / Z_{0}$ being the actual normalized admittance. For low noise transistors, manufactures usually provide $F_{\min }, R_{N}, Y_{o p t}$ by frequencies. $N$ defined by formula for desired noise figure:

$$
N=\frac{\left|\Gamma_{s}-\Gamma_{o p t}\right|^{2}}{1-\left|\Gamma_{S}\right|^{2}}=\frac{F-F_{\min }}{4 R_{N} / Z_{0}}\left|1+\Gamma_{o p t}\right|^{2}
$$

\subsection{Condition for Matching}

The scattering coefficients of transistor were determined. The only flexibility permitted to the designer is the input/output matching circuit. The input circuit should match to the source and the output circuit should match to the load in order to deliver maximum power to the load. After stability of active device is demand, input/output matching circuits should be designed so that reflection coefficient of each port is correlated with conjugate complex number as given below [8],[9]:

$$
\begin{gathered}
\Gamma_{I N}=\Gamma_{S}^{*}=S_{11}+\frac{S_{12} S_{21} \Gamma_{L}}{1-S_{22} \Gamma_{L}} \\
\Gamma_{\text {OUT }}=\Gamma_{L}^{*}=S_{22}+\frac{S_{12} S_{21} \Gamma_{S}}{1-S_{11} \Gamma_{S}}
\end{gathered}
$$

The noise figure of the first stage of the receiver overrules noise figure of the whole system. To get a minimum noise figure using a transistor, power reflection coefficient should match with $\Gamma_{\text {opt }}$ and load reflection coefficient should match with $\Gamma_{\text {out }}^{*}$

$$
\Gamma_{s}=\Gamma_{\text {opt }}
$$




\section{DESIGN OF LNA}

The Figure 4(a) is the matching network for input matching network port, while the Figure 4(b) is the matching network uses for output port respectively to provider the good performance in term of stability, power gain and S-Parameter. The goals in LNA design are to maximize its gain and minimize its noise figure with sufficient linearity and impedance matching [4],[9],[10],[11]. In order to achieve the key demands for WiMAX receiver characteristics, a LNA is designed should be met are the noise figure less than $3 \mathrm{~dB}$ and power gain should be more than $15 \mathrm{~dB}$. Also good input and output impedance matching to achieved the sparameter values.

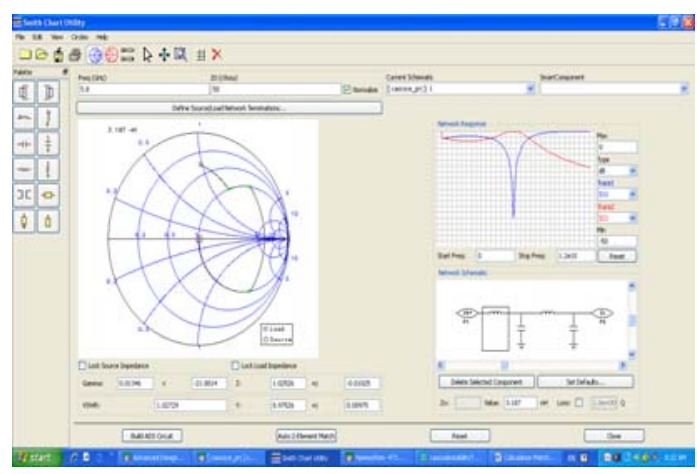

(a)

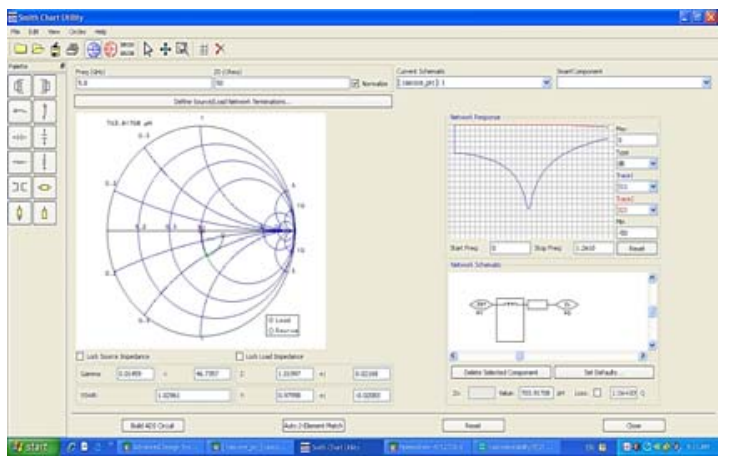

(b)

Figure 4(a) and (b). The Ladder matching network for Input and output

Figure 5(a) shows, the complete schematic circuit of $5.8 \mathrm{GHz}$ a single stage of Low noise amplifier. It was simulated using the same software to fine and further optimized for a better performance. For purpose of fabrication, the inductance and capacitance need to be converted to micro strip layout. Figure 5(b) shows, the complete schematic layout. The Duriod 5880 TYL-0200 was selected for fabricate. The LNA parameter is shown in a Table 1.

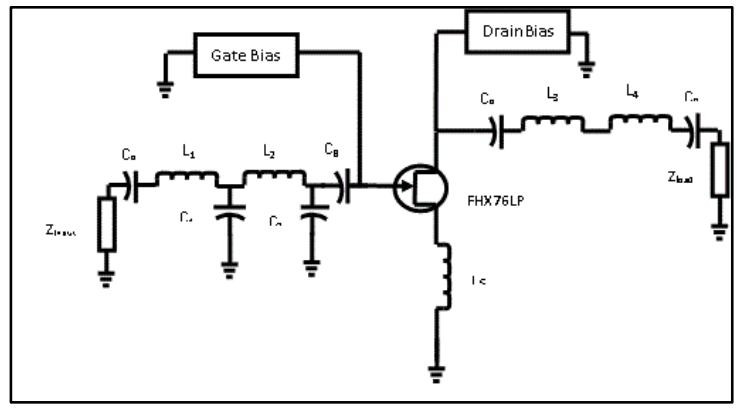

(a)

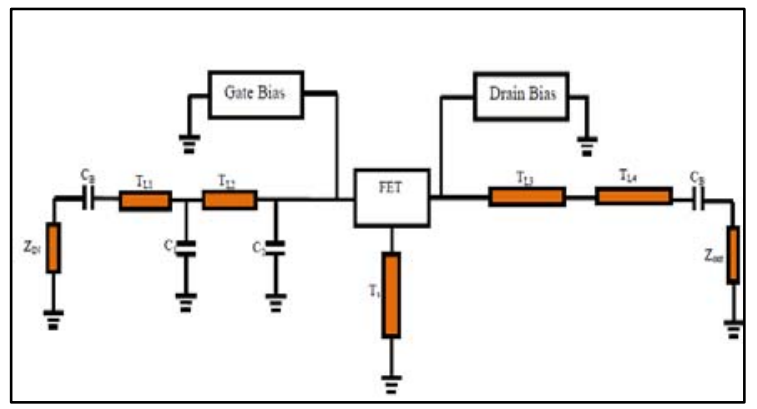

(b)

Figure 5(a) and (b): The Schematic Circuit and Layout of LNA

Table 1. LNA Parameters

\begin{tabular}{ccc}
\hline & Table 1. & \\
\hline Component & Width $(\mathrm{mm})$ & Length $(\mathrm{mm})$ \\
\hline $\mathrm{TL}_{1}=3.24 \mathrm{nH}$ & $\mathrm{W}=1.554$ & $\mathrm{~L}=15.25$ \\
$\mathrm{TL}_{2}=1.23 \mathrm{nH}$ & $\mathrm{W}=1.554$ & $\mathrm{~L}=6.07$ \\
$\mathrm{TL}_{3}=0.40 \mathrm{pF}$ & $\mathrm{W}=1.554$ & $\mathrm{~L}=12.44$ \\
$\mathrm{TL}_{3}=0.24 \mathrm{pF}$ & $\mathrm{W}=1.554$ & $\mathrm{~L}=10.44$ \\
$\mathrm{TL}_{4}=1.55 \mathrm{nH}$ & $\mathrm{W}=1.554$ & $\mathrm{~L}=7.64$ \\
$\mathrm{TL}_{5}=1.62 \mathrm{nH}$ & $\mathrm{W}=1.554$ & $\mathrm{~L}=7.98$ \\
\hline
\end{tabular}




\section{SIMULATION RESULT}

The simulated results of S-Parameter output of the microwave LNA are shown in Figure 6. It is simulated using Advanced Design System (ADS). The simulation recorded that the power gains $\mathrm{S}_{21}$ is 17.2 $\mathrm{dB}$. The input return loss $\mathrm{S}_{11}$ is $-18.9 \mathrm{~dB}$, overall noise figure (NF) of $0.914 \mathrm{~dB}$ and the output return loss $\mathrm{S}_{22}$ is $-19.6 \mathrm{~dB}$. The reflection loss $\mathrm{S}_{12}$ is $-19.9 \mathrm{~dB}$. These values were within the design specification and were accepted. Figure 6(a) shows the forward transfer and output return loss. While, Figure 6(b) shows the input reflection and the output reflection loss. Figure 6(c) and (d) are shows the Noise Figure and Stability Factor respectively.

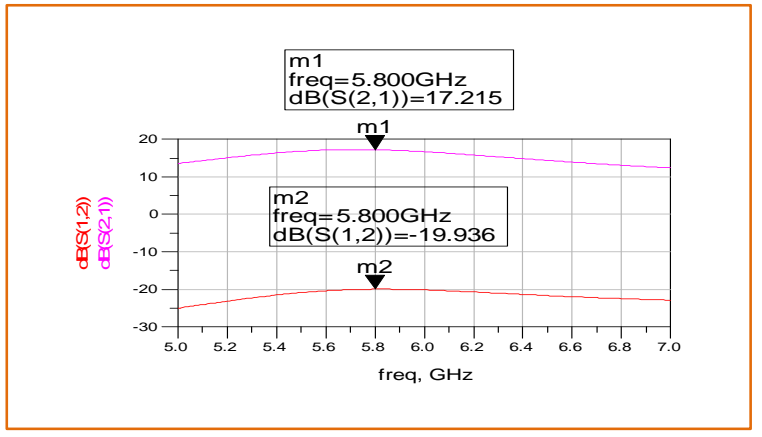

Figure 6(a). $S_{21}$ and $S_{12}$

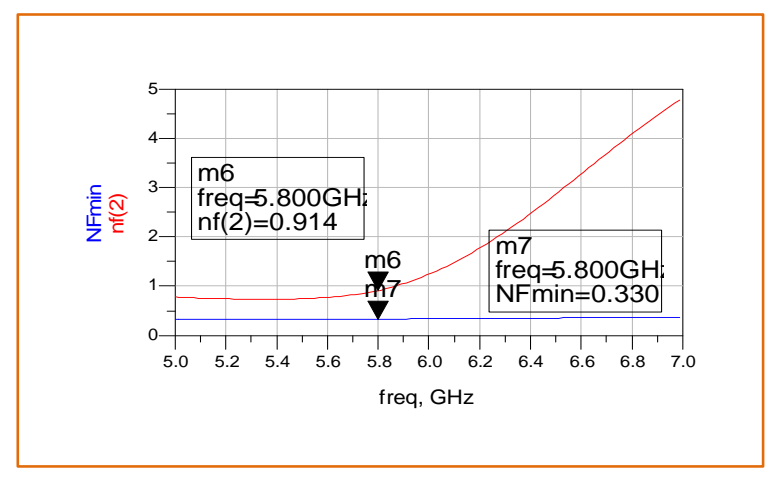

Figure 6(c). Noise Figure

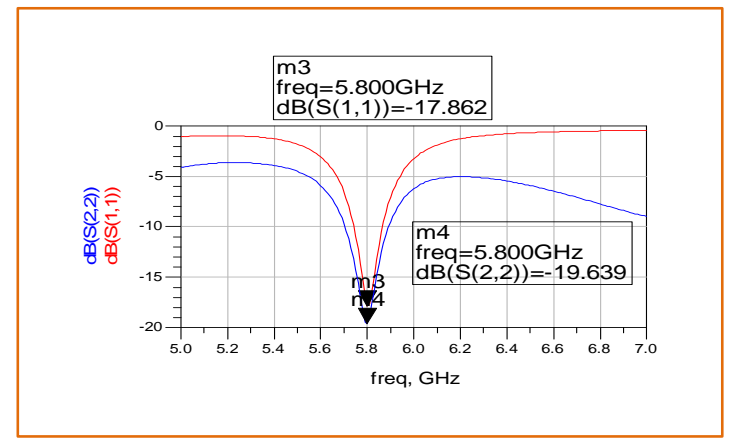

Figure 6(b). $\mathrm{S}_{11}$ and $\mathrm{S}_{22}$

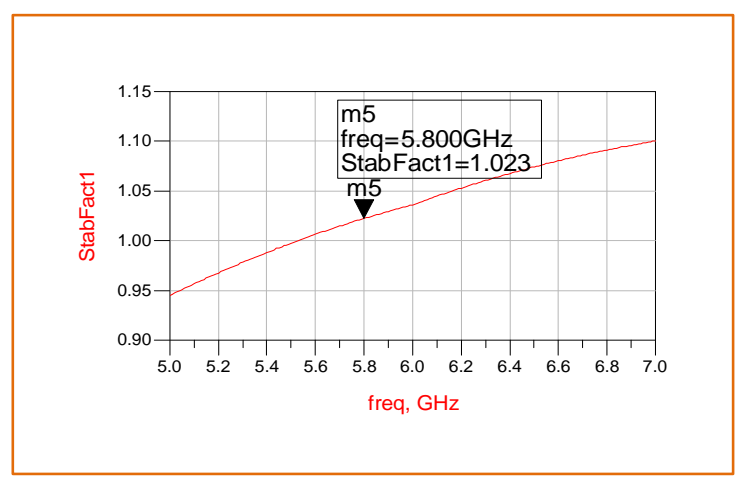

Figure 6(d). Stability Factor

\section{MEASUREMENT RESULT}

The measurement setup shown in Figure 7, the $S$ parameter of the amplifier; $S_{11}, S_{12}, S_{21}$ and $S_{22}$ are measured using the network analyzer. Gain and Noise Figure also are measured using in same setup. Before recording all measurement, a standard procedure of calibration is conducted to ensure that the measurement tools were calibrated.

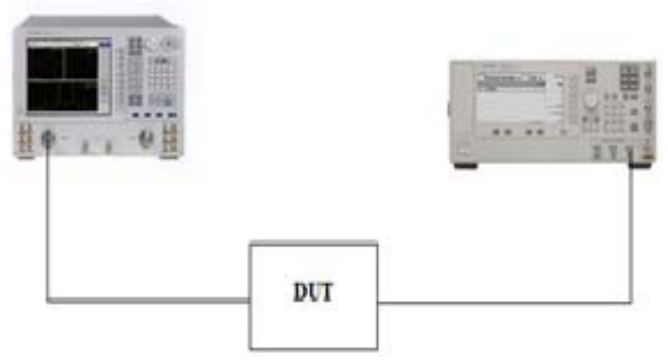

Figure 7. Setup for device under test S Measurement using Network Analyzer 
The measurement result for a microwave LNA is presented in Table 2. The $S_{11}$ parameter measured is $-10.5 \mathrm{~dB}$. This is $-0.6 \mathrm{~dB}$ less than targeted value which is better and acceptable. $\mathrm{S}_{22}$ measured is $-13.3 \mathrm{~dB}$ which is less than targeted and acceptable. The return loss required $\mathrm{S}_{12}$ obtained is less than $-21.8 \mathrm{~dB}$. The related measured gain $S_{21}$ for the LNA amplifier is $16.8 \mathrm{~dB}$ measured using the setup. The noise figure values obtained is $1.20 \mathrm{~dB}$ which complied with the targeted value of less $3 \mathrm{~dB}$. The use of ladder matching network and microstrip line matching technique at the input of the LNA contributes the best performance for the amplifier [12],[13]. This matching technique was used to provide high-loaded Q factor for better sensitivity and thus minimized the noise figure.

Table 2. Measurement Results

\begin{tabular}{ccc}
\hline & Targeted & Measured \\
\hline Input Reflection $\mathrm{S}_{11} \mathrm{~dB}$ & $<-10 \mathrm{~dB}$ & -10.6 \\
Return Loss $\mathrm{S}_{12} \mathrm{~dB}$ & $<-10 \mathrm{~dB}$ & -31.8 \\
Forward transfer $\mathrm{S}_{21} \mathrm{~dB}$ & $>15 \mathrm{~dB}$ & 16.8 \\
Output Reflection $\mathrm{S}_{22} \mathrm{~dB}$ & $<-10 \mathrm{~dB}$ & -13.3 \\
$\mathrm{NF} \mathrm{dB}$ & $<3 \mathrm{~dB}$ & 1.20 \\
BW MHz & $>1000$ & 1200 \\
\hline
\end{tabular}

The elements of Ladder-network were realized in the form of lump reactive elements and micro strip line impedance. The $3 \mathrm{~dB}$ bandwidth for the amplifier is measured using setup. It is shown in Figure 8. The 3dB bandwidth obtained is $1.2 \mathrm{GHz}$ compliant with targeted result of more than $1 \mathrm{GHz}$. It is observed that the $3 \mathrm{~dB}$ gain is $16.8 \mathrm{~dB}$. The measured parameters for the LNA were also compliant with the equation (1) to (9) using MathCAD analysis. Table III shows the performance summary of the measurement result of previously published researchers in comparison with results obtained in the proposed design. It is proven that the achieved noise figure for proposed LNA is $1.2 \mathrm{~dB}$ which is much better than others.

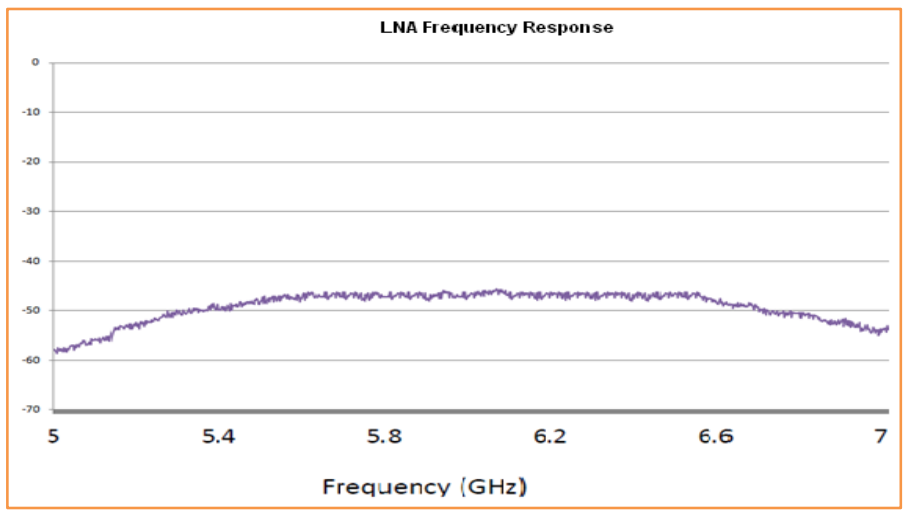

Figure 8. Frequency Response

Table 3. Comparison of measurement results

\begin{tabular}{ccccc}
\hline Published Works & Architectures & Gain (dB) & NF (dB) & BW (MHz) \\
\hline Park, et. al., 2010 [7] & Single Stage & 23 & 5.6 & 54 \\
Lin et. al., 2010 & Single Stage & 12.3 & 4.2 & 7500 \\
G.L.Ning, et. al., 2011 [4] & Single Stage & 5.9 & 1.7 & 3400 \\
Jin-Fa Chang, et. al., 2012 & Single Stage & 9.7 & 6.0 & 6500 \\
This work & Single Stage & 16.8 & 1.2 & 1200 \\
\hline
\end{tabular}

\section{CONCLUSION}

The microwave low noise amplifier with ladder matching network has been measured and designed. It's observed to compliant with IEEE standard 802.16 WiMAX applications. It is observed that the measured and targeted results giving almost the same figure as required. It observed that the gain of the measured analysis is $16.8 \mathrm{~dB}$. It is important to take note when designing the amplifier to match the amplifier circuits. The $5.8 \mathrm{GHz}$ microwave LNA has been developed successfully and the circuit contributed to the front end receiver at the described frequency. For better performance in gain of the amplifier, it can be achieved by 
increasing the number of stages to improve the gain and noise figure of the design [12]-[15]. Higher gain would expand the coverage or communication distance.

\section{ACKNOWLEDGMENTS}

I would like to take this opportunity to thank the Research Management \& Innovation Centre (RMIC) of Sultan Idris Education University for permitting and supporting in this research (2015-0052-10401).

\section{REFERENCES}

[1] M. Steer, “Microwave and RF Design,” A System Approach International Edition, 2010.

[2] R. L. Wang, et al., "2 - 6 GHz Current-Reused LNA with Transformer-type Inductors,” IEEE Proceeding, 2008.

[3] C. P. Chang, et al., "Linearity Improvement of Cascode CMOS LNAUsing a Diode Connected NMOS Transistor With A Parallel RC Circuit,” Progress in Electromagnetic Research, vol. 17, pp. 29-38, 2010.

[4] G. L. Ning, et al., "Design of Concurrent Low Noise amplifier For Multi-Band Applications," Progress Electromagnetic Research, vol. 22, pp. 165-178, 2011.

[5] M. A. Leon, et al., "Comparison of LNA Topology for Wimax Application in a Standard 90-nm CMOS Process," 12th International Conference on Computer Modelling and Simulation, pp. 642-647, 2010.

[6] D. M. Pozar, "Microwave and RF Wireless System,” Third Avenue, N.Y. John Wiley \& Sons, 2001.

[7] J. Park, et al., "A Direct Conversion CMOS RF Receiver Reconfigurable From 2 to 6 GHz," IEEE Transactions On Microwave Theory and Techniques, vol. 58, pp. 2326-2333, 2010.

[8] G. Gonzalez, "Microwave Transistor Amplifier," 1996.

[9] B. Liu and J. Mao, "Design of a 0.5 V CMOS Cascode Low Noise Amplifier for Multi-Gigahertz Applications," Journal of Semiconductor, vol/issue: 33(1), 2012.

[10] A. B. Ibrahim, et al., "The Cascode LNA with RF Amplifier at 5.8 GHz Using T-Matching Network for WiMAX Applications," Journal of Telecommunication Electronic and Computer Engineering, vol/issue: 4(1), pp. 15-21, 2012.

[11] T. V. Hoi, et al., "Design and Fabrication of High Gain Low Noise Amplifier at 4Ghz," International Journal of Engineering and Innovation Technology (IJEIT), vol/issue: 4(7), 2015.

[12] "IEEE Computer Society and IEEE Microwave Theory Technique and Society," Part 16 Air Interface For Fix Broadband Wireless System, IEEE Standard 802.16, 2004.

[13] I. J. Bahl, "Fundamentals of RF and Microwave Transistor Amplifier, 2009.

[14] A. B. Ibrahim, et al., "Low Noise Amplifier with Cascode and Cascaded Techniques at $5.8 \mathrm{GHz}$ Using T-Matching Network for WiMAX Applications,” International Journal of Electrical and Computer Engineering (IJECE), vol/issue: 1(1), pp. 1-8, 2011.

[15] K. Pongot, et al., "Design and Analysis High Gain PHEMT LNA for Wireless Application at 5.8 GHz," International Journal of Electrical and Computer Engineering (IJECE), vol/issue: 5(3), pp. 611-620, 2015.

\section{BIOGRAPHIES OF AUTHORS}

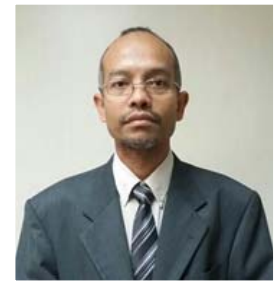

Abu Bakar Ibrahim received the B.Sc degree in electrical engineering and master degree from Universiti Teknologi Malaysia in 1998 and 2000 respectively. I am received the PhD in Electronic Engineering (Communication) from Universiti Teknikal Malaysia Melaka in year’s 2013. Research interest includes the development of low noise amplifier, Radio Frequency ommunication System, Instructional Technology, Engineering Technology and Engineering Education. Currently, I am, works at Sultan Idris Education University, Perak of Malaysia

Email: bakar@fskik.upsi.edu.my

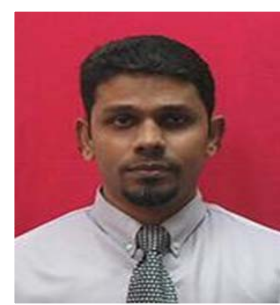

Ahmad Zamzuri Mohammad Ali received B.Sc degree in electrical engineering and master degree of Universiti Teknologi Malaysia 1998 and 2000 respectively. He received $\mathrm{PhD}$ in Multimedia (Education) from Universiti Sains Malaysia. He research interest includes the Multimedia Design, Intructional Technology, ICT in Education, Open Source Education and User Interaction. Now he joined Sultan Idris Education University, Perak of Malaysia.

Email: zamzuri@fskik.upsi.edu.my 